\title{
Numerical and Experimental Analysis of the Aging Impact on the Cooling Capacity of a Natural Ester- Based Oil Used in Power Transformers
}

\author{
A. Ortiz, Alfredo*; F. Delgado, F. Ortiz; I. Fernández; A. Santisteban \\ Department of Electrical and Energy Engineering, ETSI Industriales y T., University of Cantabria \\ Av. Los Castros s/n, 39005 Santander, Spain \\ *e-mail: ortizfa@unican.es
}

\begin{abstract}
An experimental and numerical research was conducted to study the aging effect on the cooling performance of a natural ester-based oil habitually used in power transformers. A monitored experimental platform has been used to observe the temperature increases with the aging of the insulation system (oil and paper). Three samples with three aging levels were tested at three load levels: underload, rated and overload regimes. The two aged samples (6 liters each) were aged in an accelerated way within an oven: 1 week at $150{ }^{\circ} \mathrm{C}$. Also, some physicochemical properties of the insulation system (paper and oil) were determined. A 2D numerical model has been developed with COMSOL Multiphysics to determine the temperature and velocity distributions of the different samples in the platform to analyze their differences and to compare their cooling capacity. At first sight, the aging affects negatively to the cooling capacity of the new alternative liquid based on natural esters.
\end{abstract}

\section{INTRODUCTION}

Several works have studied the cooling capacity of alternative dielectric liquids in comparison with that of mineral oil, [1-3]. However, the authors of this work have not found many articles in the scientific literature in which the impact of the insulation system aging on the cooling capacity of the liquid have been studied. In fact, the only work that studies this topic belongs to Kassi et al. In 2016, they carried out an experimental and numerical analysis using mineral oil as a coolant. The results of a 2D axisymmetric numerical model of a 3-phase power transformer column comparing fresh with aged oil showed the worsening of the cooling capacity with aging, thus resulting in an enlargement of the hot-spot, [4].

Based on the above, this paper presents a numerical and experimental study of the cooling capacity of a commercial natural ester-based oil with three levels of aging. Temperature variations with the degradation of the oil are obtained in an experimental platform. Also, a 2D numerical study of this experimental setup has been developed to determine its temperature and velocity distributions.

\section{THERMAL AGING AND PHYSICOCHEMICAL PROPERTIES MEASUREMENT}

The aging procedure and the variation of the dynamic viscosity of the liquid with temperature are presented in subsection A and B.

\section{A. Aging method}

The thermal-hydraulic behavior of three types of aged oil samples were studied in a stainless-steel tank with a 1-phase transformer (800VA, 230/115V) as heat source, see Fig. 1.

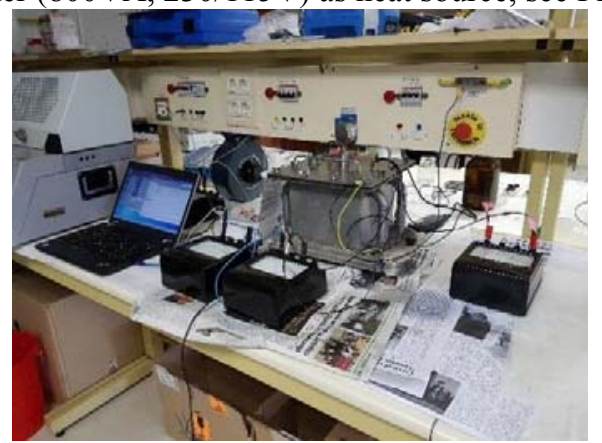

Figure 1. Experimental platform

The first sample was a fresh oil which has not suffered any kind of thermal stress. The second sample was obtained through an accelerated thermal aging test in which the natural ester was thermally aged without any additional material. Finally, the last type of oil was obtained by thermal aging of the natural esterbased oil and pressboard 3055 (PSP 3055) strips, see Fig. 2.

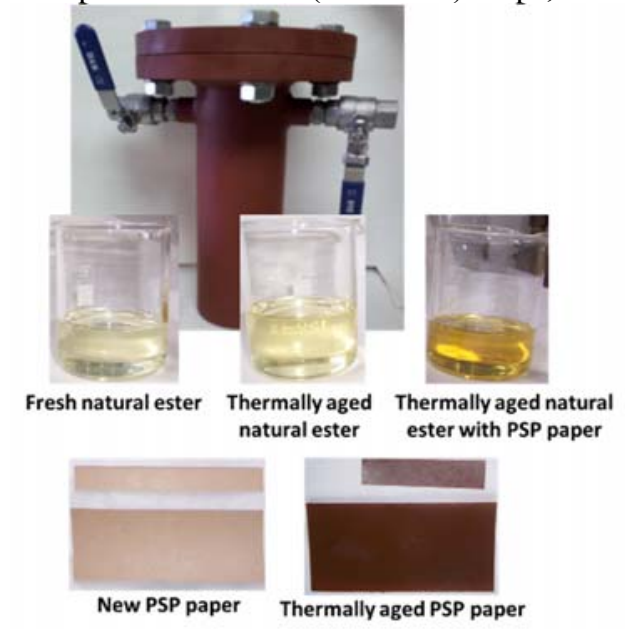

Fig. 2. PSP paper strips, oils and steel vessel

Six sealed vessels for each sample of aged oil were prepared by inserting $1000 \mathrm{ml}$ of natural ester with a nitrogen headspace of $25 \%$ by volume, and $150 \mathrm{~g}$ of PSP 3055 in the case of the third sample of oil. An accelerated thermal ageing was then 
carried out at $150^{\circ} \mathrm{C}$ for 168 hours. After aging time, the vessels were cooled at room temperature $\left(25^{\circ} \mathrm{C}\right)$ for five hours.

\section{B. Experimental determination of the oil viscosity}

Small quantities of the oil samples are taken to evaluate their dynamic viscosity since the heat carrier capacity of these fluids strongly depends on this property. In fact, the variation of the property with the temperature is determined using a rotational viscometer, see Fig. 2.

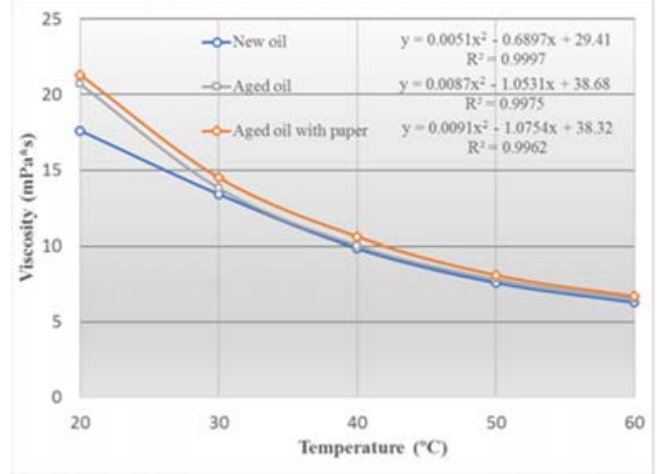

Figure 3. Dynamic viscosity evolution with the temperature

As can be seen in Fig. 3, the higher the aged oil degradation, the higher the viscosity. Also, the viscosities of the two aged oils are similar. Nonetheless, it is needed to point out that the difference between viscosities diminish with the temperature.

\section{EXPERIMENTAL SETUP}

The experiment developed is based on that used by Patel et al. to determine the cooling performance of a ferrofluid in a sealed distribution transformer prototype, [5]. The temperatures inside the tank are monitored by means of three probes (see pentagons in Fig. 4). Two of them are located in the bottom and in the top of the tub to measure the oil temperature. Other sensor measures the hot-spot winding temperature. Ambient temperature is also measured to use it as a reference. A microcontroller (Arduino) and an Integrated Development Environment (IDE) is used to capture and to record the measurements of the sensors every five minutes until steady-state is reached.

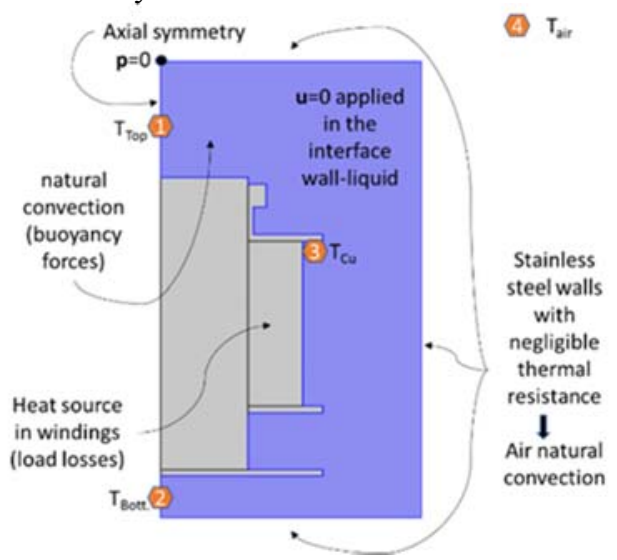

Figure 4. 2D section of the platform.

Using this platform, several short circuit tests have been carried out in which three load level cases $(\mathrm{C}=0.72, \mathrm{C}=1, \mathrm{C}=1.3)$ are considered, with negligible no-load losses. The rated currents of the transformer considered are $3.5 \mathrm{~A}$ in the primary winding $(230 \mathrm{~V})$ and $7 \mathrm{~A}(115 \mathrm{~V})$ in the secondary winding $(115 \mathrm{~V})$.

\section{NUMERICAL MODEL}

This section presents the description of the numerical model that allow us to study the physical phenomena that occur in the experimental platform. This model has been carried out using the software tool COMSOL Multiphysics 5.3.

\section{A. Governing equations}

This study is based on the numerical solution of the momentum and continuity equations in laminar regime, (1) and (2), respectively. It also solves the heat transfer equation, (3).

$$
\begin{gathered}
\rho(\boldsymbol{u} \cdot \nabla) \boldsymbol{u}=\nabla \cdot\left[-p \boldsymbol{I}+\mu\left(\nabla \boldsymbol{u}+(\nabla \boldsymbol{u})^{T}\right)-\frac{2}{3} \mu(\nabla \cdot \boldsymbol{u}) \boldsymbol{I}\right]+\boldsymbol{F} \\
\nabla \cdot(\rho \mathbf{u})=0 \\
\rho C_{p} \mathbf{u} \cdot \nabla \mathrm{T}=\nabla \cdot(\mathrm{k} \nabla T)+q
\end{gathered}
$$

The symbols $\rho, \mathrm{u}, \mathrm{p}, \mathbf{I}, \mu, \mathrm{F}, \mathrm{Cp} \mathrm{T}$ and $\mathrm{q}$ of (1), (2) and (3) are density, velocity vector, pressure, identity matrix, dynamic viscosity, body force vector (buoyancy forces), specific heat capacity, temperature and unitary heat transfer, respectively.

\section{B. Boundary conditions}

Several assumptions and simplifications have been considered to obtain the $2 \mathrm{D}$ numerical model of the experimental setup. As shown in Fig. 4, several thermal and hydraulic boundary conditions are considered. Also, the constant heat source in the windings (load losses) and the buoyancy forces due to density differences in the liquid are indicated.

\section{Mesh study}

The computational domain considers both the liquid and solid part of the geometry to calculate the temperature distribution in the entire model and the fluid behavior in the tank.

Initially, in the meshing study, several mesh types with different meshing densities are studied, thus obtaining several configurations with similar solutions. Finally, a high-density mesh in which free triangular elements are combined with rectangular boundary layers is selected (See Fig. 5). This mesh configuration allows to capture the temperature and velocity boundary layers in the interface solid-liquid and the temperature stratification in the fluid that produce the convection cycles.

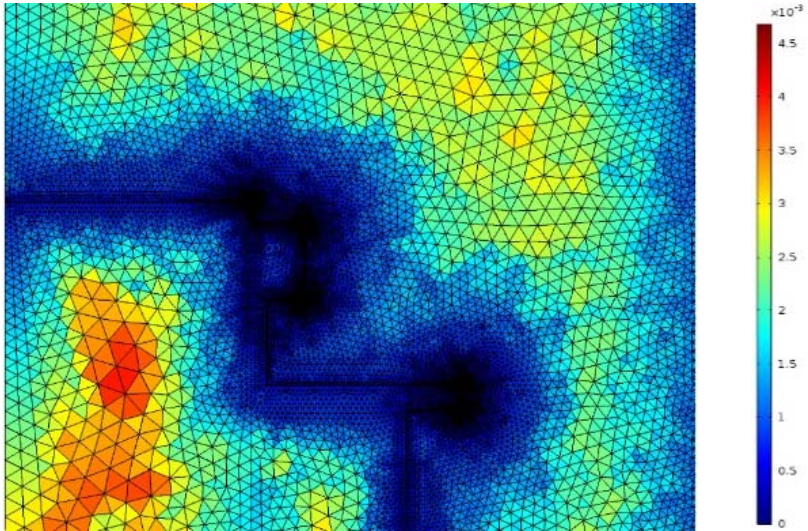

Fig. 5. Detail of the mesh size. 


\section{MODEL VALIDATION}

The 2D numerical model has been validated by comparison of the temperatures measured by sensors in the experimental platform with those of the virtual probes used in the model, see Table I.

TABLE I

TESTS VS. MODEL TEMPERATURES PROBES

\begin{tabular}{|c|c|c|c|c|c|c|}
\hline & $\mathrm{C}$ & & $\mathrm{T}_{\text {air }}$ & $\mathrm{T}_{\text {Top }}$ & $\mathrm{T}_{\mathrm{Cu}}$ & $\mathrm{T}_{\text {Bott }}$ \\
\hline \multirow{9}{*}{ 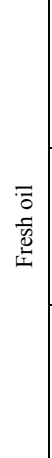 } & \multirow{3}{*}{0.72} & Num. model & \multirow{2}{*}{24.5} & 34.8 & 36.1 & 33.2 \\
\hline & & Exper. test & & 33.8 & 37.0 & 32.5 \\
\hline & & Perc. Diff. (\%) & - & 3.0 & -2.3 & 2.2 \\
\hline & \multirow{3}{*}{1} & Num. model & \multirow{2}{*}{26} & 44.6 & 46.9 & 41.5 \\
\hline & & Exper. test & & 43.3 & 47.9 & 40.6 \\
\hline & & Perc. Diff. (\%) & - & 2.9 & -2.1 & 2.1 \\
\hline & \multirow{3}{*}{1.3} & Num. model & \multirow{2}{*}{24.8} & 52.9 & 56.5 & 47.8 \\
\hline & & Exper. test & & 52.1 & 57.8 & 47 \\
\hline & & Perc. Diff. (\%) & - & 1.5 & -2.3 & 1.7 \\
\hline \multirow{9}{*}{$\begin{array}{l}\bar{\sigma} \\
\overline{0} \\
\overline{8} \\
\overline{8}\end{array}$} & \multirow{3}{*}{0.72} & Num. model & \multirow{2}{*}{25.3} & 35.8 & 37.2 & 34.1 \\
\hline & & Exper. test & & 35.1 & 38.5 & 33.8 \\
\hline & & Perc. Diff. (\%) & - & 1.9 & -3.4 & 0.8 \\
\hline & \multirow{3}{*}{1} & Num. model & \multirow{2}{*}{24.1} & 43.0 & 45.3 & 39.7 \\
\hline & & Exper. test & & 42.0 & 46.4 & 39.0 \\
\hline & & Perc. Diff. (\%) & - & 2.4 & -2.4 & 1.8 \\
\hline & \multirow{3}{*}{1.3} & Num. model & \multirow{2}{*}{27} & 57.0 & 60.6 & 51.7 \\
\hline & & Exper. test & & 56.1 & 61.5 & 50 \\
\hline & & Perc. Diff. (\%) & - & 1.6 & -1.5 & 3.3 \\
\hline \multirow{9}{*}{ 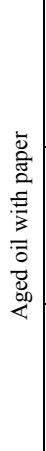 } & \multirow{3}{*}{0.72} & Num. model & \multirow{2}{*}{24} & 35.8 & 37.2 & 34.1 \\
\hline & & Exper. test & & 34.1 & 39.2 & 34 \\
\hline & & Perc. Diff. (\%) & - & 5.0 & -5.0 & 0.4 \\
\hline & \multirow{3}{*}{1} & Num. model & \multirow{2}{*}{23.8} & 43.2 & 45.7 & 40.0 \\
\hline & & Exper. test & & 41.5 & 47.6 & 39.5 \\
\hline & & Perc. Diff. (\%) & - & 4.2 & -4.0 & 1.2 \\
\hline & \multirow{3}{*}{1.3} & Num. model & \multirow{2}{*}{24.1} & 55.6 & 59.3 & 50.3 \\
\hline & & Exper. test & & 53.1 & 61 & 48.9 \\
\hline & & Perc. Diff. (\%) & - & 4.7 & -2.9 & 2.8 \\
\hline
\end{tabular}

All the errors of the virtual probes regarding platform sensors are within the range \pm 5 . This way, the model is accurate enough to use it in the determination of the thermal-hydraulic behavior of the liquids.

\section{RESULTS}

\section{A. Experimental results}

Table II shows the temperature increments regarding ambient temperature measured in the experimental tests. As it can be seen in this table, from the oil cooling capacity standpoint, its aging worsens this capability: considering the same load index, the higher the aging, the higher the temperatures at the top and bottom of the tank. This clearly affects to the hot-spot winding temperature, increasing also with the aging.

TABLE II

EXPERIMENTAL TEMPERATURES GRADIENTS

\begin{tabular}{|c|r|c|c|c|}
\hline $\mathrm{C}$ & Aging & $\Delta \mathrm{T}_{\text {Top }}$ & $\Delta \mathrm{T}_{\mathrm{Cu}}$ & $\Delta \mathrm{T}_{\text {Bott }}$ \\
\hline \multirow{3}{*}{0.72} & Fresh & 9.3 & 12.5 & 8.0 \\
\cline { 2 - 5 } & Aged & 9.8 & 13.2 & 8.5 \\
\cline { 2 - 5 } & Aged w/p & 10.1 & 15.2 & 10.0 \\
\hline \multirow{3}{*}{1} & Fresh & 17.3 & 21.9 & 14.6 \\
\cline { 2 - 5 } & Aged & 17.9 & 22.3 & 14.9 \\
\hline \multirow{3}{*}{1.3} & Aged w/p & 17.7 & 23.8 & 15.7 \\
\cline { 2 - 5 } & Fresh & 27.3 & 33 & 22.2 \\
\cline { 2 - 5 } & Aged & 29.1 & 34.5 & 23.0 \\
\hline
\end{tabular}

Finally, considering the same sample, it is also remarkable that the higher percentage increment of the winding temperature is with the smallest load index, see Fig. 6. This is mainly due to the exponential decrement of the viscosity with the temperature, see Figs. 3.

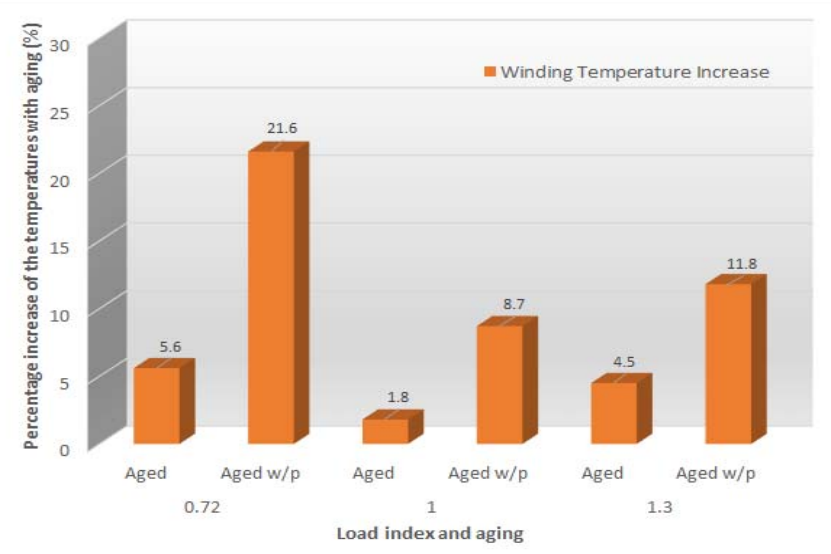

Fig. 6. Winding temperature increase with load index and aging.

\section{B. Numerical results}

Among the worst three cases (aged oil w/paper), the one with the lowest load index is the worst, since this case combines the most degraded liquid with the lowest temperatures, thus having the highest viscosity. This can be explained by the smaller vertical stratification of the oil temperatures that occur in the samples with the higher viscosities. This last assertion can be corroborated by the numerical model: the higher the load index, the higher the vertical thermal stratification, see Figure 7. Furthermore, this effect can be seen in the difference between the hot-spot and the minimum temperature of the oil. This difference will be increased with the load index. Finally, the increase of thermal stratification with temperature results in an increase in the number of convection cycles, thus improving the cooling capacity of the fluid. 


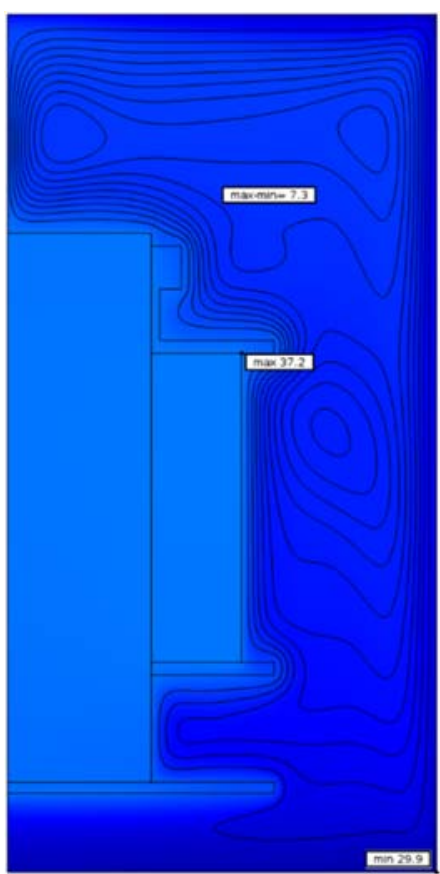

Worst case, $\mathrm{C}=0.72$

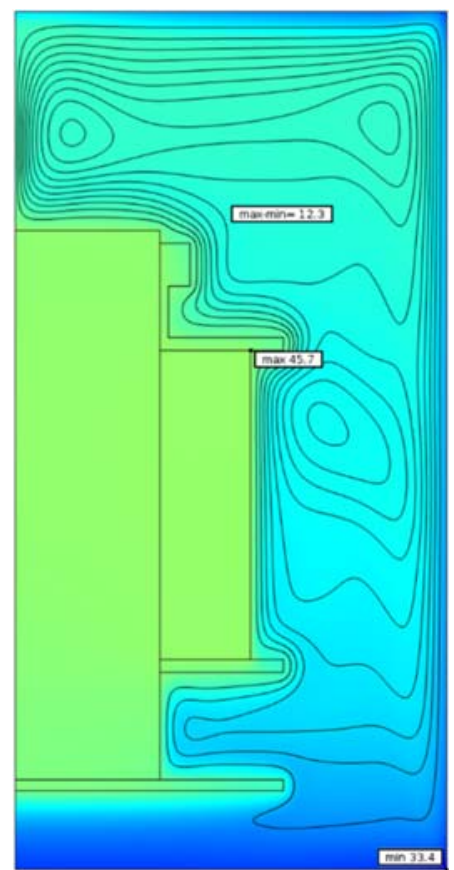

Intermediate case, $\mathrm{C}=1$

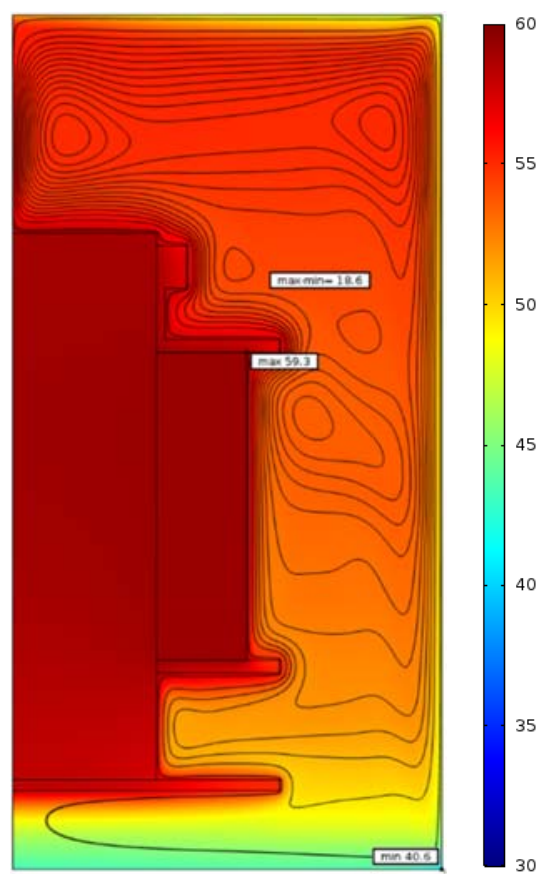

Best case, $\mathrm{C}=1.3$

Fig. 7. Thermal stratification and flow pattern (streamlines) of aged oil with paper $\left({ }^{\circ} \mathrm{C}\right)$

\section{CONCLUSIONS}

An experimental and numerical study of the cooling capacity of a biodegradable dielectric liquid is presented in this paper. The aging method of this liquid is also described. The variation of the dynamic viscosity with temperature is also provided.

Nine experimental tests and their respective simulations have been carried out and compared. As a result of this comparison, the numerical model has been validated.

The experimental results indicate that the cooling capacity of the alternative liquid worsens with aging. This is due to the higher viscosity of the aged samples. However, this negative effect is mitigated by the load index; in fact, by the operating temperature: the higher this temperature, the lower the impact of the aging on the cooling capacity. This is due to the exponential decrease of the viscosity with temperature.

All the above has been confirmed numerically. In fact, the model captures the variation of the vertical thermal stratification and the increasing number of convection cycles with temperature.

\section{ACKNOWLEDGMENT}

The research leading to these results has received funding from multiple sources over years, but we would specifically like to acknowledge the support received in the later stages from the Spanish Plan Estatal de I+D under the grant agreement DPI21571219-C2-1-R.

\section{REFERENCES}

[1] T. Park, Numerical analysis of local hot-spot temperatures in transformer windings by using alternative dielectric fluids. Electr. Eng. 97 (2015) 261-268, doi: 10.1007/s00202-015-0335-4.

[2] R. Lecuna, F. Delgado, A. Ortiz, P.B. Castro, I. Fernandez, C.J. Renedo, Thermal-fluid characterization of alternative liquids of power transformers: a numerical approach. IEEE Transac. Dielectr. Electr. Insul. 22 (2015) 2522-2529, doi: 10.1109/TDEI.2015.004793.

[3] A. Santisteban, F. Delgado, A. Ortiz, I. Fernández, C.J. Renedo, F. Ortiz, Numerical analysis of the hot-spot temperature of a power transformer with alternative dielectric liquids. IEEE Transac. Dielectr. Electr. Insul. 24 (2017) 3226-3235, doi: 10.1109/TDEI.2017.006228.

[4] K.S. Kassi, M.I. Farinas, I. Fofana, C. Volat, Analysis of aged oil on the cooling of power transformers from computational fluid dynamics and experimental measurements. J. Appl. Fluid Mech. 9 (2016) 235-243

[5] J. Patel, Performance of Mn-Zn ferrite magnetic fluid in a prototype distribution transformer under varying loading conditions. Int. J. Therm. Scien, 114 (2017) 64-71, doi: 10.1016/j.ijthermalsci.2016.12.011 